\title{
SUPLEMENTAÇÃO ENZIMÁTICA SOBRE O DESEMPENHO E TAXA DE EXCREÇÃO DE AMÔNIA EM TILÁPIA DO NILO
}

\author{
Veruska Dilyanne Silva Gomes ${ }^{1}$ \\ José Humberto Vilar da Silva ${ }^{1}$ \\ José Jordão Filho \\ Alda Lúcia de Lima Amâncio ${ }^{1}$ \\ Fernando Guilherme Perazzo Costa ${ }^{1}$ \\ Edilson Paes Saraiva ${ }^{1}$ \\ Cacio Ribeiro Cavalcanti
}

GOMES, V. D. S.; SILVA, J. H. V. da; JORDÃO FILHO, J.; AMÂNCIO, A. L. de L.; COSTA, F. G. P.; SARAIVA, E. P.; CAVALCANTI, C. R. Suplementação enzimática sobre o desempenho e taxa de excreção de amônia em tilápias do Nilo. Arq. Ciênc. Vet. Zool. UNIPAR, Umuarama, v. 22, n. 1, p. 13-20, jan./mar. 2019.

RESUMO: O uso de enzimas exógenas em rações para peixes viabiliza benefícios como a possibilidade de empregar ingredientes que possuem nutrientes pouco disponíveis aos animais, por estes não produzirem as enzimas necessárias, além de contribuir para a redução de poluentes como fósforo e nitrogênio na água. O presente estudo tem como objetivo principal avaliar o impacto da inclusão de um complexo enzimático no desempenho e taxa de excreção de amônia em tilápias. Foram formuladas duas rações experimentais, sendo uma "padrão" e uma "reformulada" valorizada com suplementação enzimática nos níveis de 0,$025 ; 0,050$ e $0,075 \%$. No primeiro ensaio parâmetros avaliados foram desempenho e índices corporais. Estes foram influenciados positivamente pela suplementação enzimática em dietas isoprotéicas e isoenergéticas. No segundo ensaio foi avaliada a taxa de amônia total $\left(\mathrm{NH}_{3}+\mathrm{NH}_{4}\right)$ dos peixes. Foram utilizadas tilápias do nilo com peso médio inicial de $21 \pm 0,4 \mathrm{~g}$; os peixes que receberam ração com inclusão de 0,025\% do complexo enzimático apresentaram as menores taxas de excreção de amônia. Recomendando a suplementação com complexo enzimático por influenciar positivamente nos índices produtivos e, ao nível de 0,025\% reduzir a excreção de amônia.

PALAVRAS-CHAVE: Aditivos alimentares. Complexo enzimático. Produtos nitrogenados. Oreochromis niloticus

\section{ENZYME SUPPLEMENTATION ON PERFORMANCE AND AMMONIA EXCRETION RATE IN NILE TILAPIA}

\begin{abstract}
The use of exogenous enzymes in fish feed provides benefits such as the ability to use ingredients with nutrients that are seldom available to the animal, since the enzymes are not produced by them, and thus contributing to the reduction of pollutants such as phosphorus and nitrogen in the water. This study aims at evaluating the impact of including an enzyme complex on the performance and ammonia excretion rate in tilapia. Two experimental diets were formulated and referred to as "standard" and "reformulated", with the addition of enzyme supplementation at $0.025 ; 0.050$ and $0.075 \%$. The first test assessed the parameters of performance and body indexes. These were positively influenced by the enzyme supplementation in diets with the same levels of protein and energy. In the second test, the total ammonia rate $\left(\mathrm{NH}_{3}+\mathrm{NH}_{4}\right)$ in fish was assessed. Nile tilapia with average weight of $21 \pm 0.4 \mathrm{~g}$ were used; the fish receiving feed with the inclusion of $0.025 \%$ enzyme complex presented the lowest ammonia excretion rates. Therefore, supplementation with enzyme complex is recommended to positively influence the production rates, and at a $0.025 \%$, to reduce the excretion of ammonia.
\end{abstract}

KEY WORDS: Food additives. Enzyme complex. Nitrogenous products. Oreochromis niloticus

\section{SUPLEMENTACIÓN ENZIMÁTICA SOBRE EL RENDIMIENTO Y TASA DE EXCRECIÓN DE AMONÍACO EN TILÁPIA DEL NILO}

RESUMEN: El uso de enzimas exógenas, en raciones para peces, viabiliza beneficios como la posibilidad de emplear ingredientes que poseen nutrientes poco disponibles a los animales, por éstos no producir las enzimas necesarias, además de contribuir a la reducción de contaminantes como fósforo y nitrógeno en el agua. El presente estudio tiene como objetivo principal evaluar el impacto de la inclusión de un complejo enzimático en el desempeño y tasa de excreción de amoníaco en tilapias. Se formularon dos raciones experimentales, siendo una "patrón” y una "reformulada" valorizada con suplementación enzimática en los niveles de 0,$025 ; 0,050$ y $0,075 \%$. En el primer ensayo los parámetros evaluados fueron rendimiento e índices corporales. Esos fueron influenciados positivamente por la suplementación enzimática en dietas isoprotéicas e isoenergéticas. En el segundo ensayo se evaluó la tasa de amoníaco total (NH3 + NH4) de los peces. Se utilizaron tilapias del Nilo con peso medio inicial de $21 \pm 0,4 \mathrm{~g}$; los peces que recibieron ración con inclusión de $0,025 \%$ del complejo enzimático presentaron las menores tasas de excreción de amoníaco. Recomendando la suplementación con complejo enzimático por influenciar positivamente en los índices productivos y, al nivel de 0,025\% reducir la excreción de amoníaco.

PALABRAS CLAVE: Aditivos alimentarios. Complejo enzimático. Productos nitrogenados. Oreochromis niloticus.

DOI: 10.25110 /arqvet.v22i1.2019.6847

1Universidade Federal da Paraíba, PB. veruska_sgomes@yahoo.com.br 


\section{Introdução}

A alimentação corresponde à maior parcela dos investimentos de produção, em sistemas de criação intensiva e superintensiva. A intensificação da produção caracterizada pelo aumento da densidade de estocagem, diminuição do tempo de cultivo e maior ganho em biomassa exige que os peixes, para que possam expressar todo o seu potencial genético, sejam alimentados com rações visando atender as exigências nutricionais que outrora eram supridas apenas com alimentação natural (FURUYA, 2010). Neste contexto, o aumento da disponibilidade de nutrientes presentes nos ingredientes que compõem as rações representa um fator essencial para elevar o padrão de qualidade do produto final.

As enzimas exógenas são adicionadas nas rações de não ruminantes com objetivo de minimizar fatores antinutricionais, aumentar a digestibilidade das rações e auxiliar enzimas endógenas em substratos que não são degradados por estas. Pesquisas avaliando a inclusão de complexos enzimáticos em rações a base de grãos para peixes onívoros, como a tilápia do nilo, têm apresentado resultados positivos no desempenho destes animais, possibilitando uma utilização eficiente do amido e proteína (MOURA et al., 2012).

A alta produção de tilápia do Nilo é justiçada pelo número de características desejáveis comercialmente como alta rusticidade, boa adaptabilidade aos sistemas de produção, boa conversão alimentar, facilidade em aceitar ração, possibilidade de aquisição de alevinos durante todo o ano, ciclos curtos de engorda, e por possuir carne com alta aceitação no mercado consumidor devido ao sabor suave de carne e ausência de espinhas no filé (MOREIRA et al., 2001).

O uso de enzimas como aditivos em dietas para tilápias apresenta benefícios como a possibilidade de empregar ingredientes de baixa digestibilidade de nutrientes (OLIVEIRA et al., 2007). Com isso, pode ocorrer redução da excreção de determinados nutrientes no meio, a exemplo do fósforo e nitrogênio que aumentam a carga poluente na água. Rodrigues et al. (2015) destacam que por ser tóxica, a amônia deve permanecer em baixas concentrações no ambiente aquático, evitando diminuição da produtividade e mortes de peixes.

Na nutrição de peixes, o uso de enzimas exógenas combinadas ou de complexos enzimáticos, tem permitido a redução de fatores antinutricionais em dietas para tilápia do Nilo (Oreochromis niloticus) (OLIVEIRA et al., 2007), pós-larvas de pacu (Piaractus mesopotamicus) (TESSER et al., 2006); melhoram a taxa de conversão alimentar no catfish (Clarias gariepinus) (YILDIRIM et al., 2010) e crescimento de juvenis de tilápia do Nilo (MOURA et al., 2012).

A inclusão de uma enzima digestiva como a protease na alimentação de tucunaré (Cichla sp.) provocam melhorias no desempenho (SOARES et al., 2008), como também a inclusão de fitase proporcionou efeito positivo no desempenho de alevinos de tambaqui (Colossoma macropomum) (MENDONÇA et al., 2012) e diminuiu o teor de extrato etéreo na carcaça da carpa húngara (ROCHA et al., 2010).

O presente trabalho foi realizado com objetivo de avaliar o desempenho e a taxa de excreção de amônia em tilápias do Nilo alimentadas com dieta padrão e dieta reformulada com redução energética, proteica, de fósforo, de cálcio e inclusão do complexo enzimático.

\section{Material e Métodos}

Para a avaliação do desempenho e taxa de excreção de amônia foram realizados dois ensaios experimentais no Laboratório de Aquicultura da Universidade Federal da Paraíba, no município de Bananeiras-PB.

Para os dois ensaios, os tratamentos foram constituídos pela dieta padrão, seguindo recomendação de Furuya (2010) com 30\% de proteína bruta, $3000 \mathrm{kcal}$ de energia bruta $/ \mathrm{kg}, 0,9552 \%$ de fósforo total e $1,5 \%$ de cálcio; e pela dieta reformulada com redução de $10 \%$ para proteína bruta, energia bruta, fósforo total apresentando $27 \%$ de proteína bruta, $2700 \mathrm{kcal}$ de energia bruta $/ \mathrm{kg}, 0,6131 \%$ de fósforo total, $1,35 \%$ de cálcio e inclusão do complexo enzimático (composto por Protease; Fitase; Xilanase; $\beta$-Glucanase; Celulase; Amilase e Pectinase) nos níveis de 0,$025 ; 0,050$ e $0,075 \%$ (Tabela 1).

Tabela 1: Composição alimentar e nutricional das dietas experimentais.

\begin{tabular}{|c|c|c|}
\hline Ingredientes (kg) & $\begin{array}{l}\text { Ração } \\
\text { Padrão }\end{array}$ & $\begin{array}{c}\text { Dieta } \\
\text { reformulada }\end{array}$ \\
\hline Farelo de soja & 45,520 & 36,630 \\
\hline Milho & 32,990 & 44,600 \\
\hline Farinha de peixes & 10,000 & 10,000 \\
\hline Farelo de trigo & 6,000 & 3,839 \\
\hline Óleo de soja & 3,480 & 1,080 \\
\hline Fosfato bicalcico & 0,930 & 0,636 \\
\hline Sal comum & 0,300 & 0,300 \\
\hline $\begin{array}{l}\text { Suplemento mineral e } \\
\text { vitamínicol }\end{array}$ & 0,500 & 0,500 \\
\hline Cloreto de colina & 0,150 & 0,150 \\
\hline BHT & 0,020 & 0,020 \\
\hline Complexo enzimático ${ }^{2}$ & 0,000 & 0,000 \\
\hline Inerte & 0,100 & 0,200 \\
\hline Calcário & 0,000 & 1,564 \\
\hline L-Lisina HCL & 0,000 & 0,295 \\
\hline L-Treonina & 0,000 & 0,131 \\
\hline \multirow[t]{3}{*}{ DL-Metionina } & 0,000 & 0,043 \\
\hline & 100,00 & 100,00 \\
\hline & \multicolumn{2}{|c|}{ Composição nutricional (\%) } \\
\hline Matéria seca & 85,640 & 85,880 \\
\hline Proteína Bruta (\%) & 30,000 & 27,000 \\
\hline Energia Bruta (kcal/kg) & 3000 & 2700 \\
\hline Fibra bruta (\%) & 3,946 & 3,453 \\
\hline Fósforo total (\%) & 0,955 & 0,613 \\
\hline Cálcio & 1,500 & 1,500 \\
\hline Metionina + cistina total & 0,962 & 0,924 \\
\hline Metionina total & 0,522 & 0,522 \\
\hline Treonina total & 1,190 & 1,190 \\
\hline
\end{tabular}

${ }^{1}$ Níveis de garantia por quilograma do produto: Vit. A, 500.000UI; Vit. D3, 200.000UI; Vit. E, 5.000mg; Vit. K3, 1.000mg; Vit. B1, $1.500 \mathrm{mg}$; Vit. B2, 1.500mg; Vit. B6, 1.500mg; Vit. B12, 4.000mg; Ác. Fólico, 500mg; Pantotenato Ca, 4.000mg; Vit. C, 15.000mg; 
Biotina, 50mg; Inositol, 10.000; Nicotinamida, 7.000; Co, 10mg; Cobre, 500mg; Fe, 5.000mg; I, 50mg; Mn, 1500mg; Se, 10mg; Zn, $5.000 \mathrm{mg} . /{ }^{2}$ Complexo enzimático composto por Protease, Fitase, Xilanase, $\beta$-Glucanase, Celulase, Amilase e Pectinase.

Para a confecção das rações, os ingredientes foram moídos em triturador tipo martelo com peneira de $0,8 \mathrm{~mm}$. Posteriormente, foi realizada a mistura dos ingredientes e incorporado o complexo enzimático. As rações foram misturadas em misturador "Y", peletizadas, resfriadas e armazenadas em refrigerador.

\section{Ensaio I - Desempenho de tilápias em função da suple- mentação enzimática}

Os parâmetros físico-químicos da água: o oxigênio dissolvido, dureza, alcalinidade e $\mathrm{pH}$, foram mensurados três vezes por semana, enquanto a temperatura da água foi mensurada duas vezes ao dia todos os dias, pela manhã $(8 \mathrm{~h} 00 \mathrm{~min})$ e à tarde $(16 \mathrm{~h} 00 \mathrm{~min})$. As variáveis $\mathrm{pH}$, oxigênio dissolvido e temperatura foram mensuradas, respectivamente, com o auxílio de peagâmetro (HANNA®) e Oxímetro/ termômetro (ICEL $®)$.

O ensaio foi realizado por um período de 60 dias. Foram utilizados 250 alevinos de tilápia do nilo (Oreochromis niloticus) da linhagem Supreme, machos, com peso médio inicial de $17,36 \pm 1,2 \mathrm{~g}$ e comprimento total médio inicial de 9,71 $\pm 0,24 \mathrm{~cm}$. Os animais foram distribuídos em um delineamento inteiramente casualizado com cinco tratamentos e quatro repetições. A unidade experimental foi formada por tanques-rede experimentais com $0,25 \mathrm{~m}^{3}$ de capacidade total. Os peixes foram alimentados três vezes ao dia $(8 \mathrm{~h} 00 \mathrm{mim}$, $11 \mathrm{~h} 00 \mathrm{~min}$ e $15 \mathrm{~h} 00 \mathrm{~min}$ ).

Ao final do experimento os peixes foram submetidos a 12 horas de jejum para esvaziamento completo do trato digestório, posteriormente foram insensibilizados e abatidos em gelo, pesados, medidos e eviscerados para análises dos índices corpóreos e rendimento de carcaça. Foram avaliados o peso final; ganho em peso: $\mathrm{GP}=$ (peso final)-(peso inicial); conversão alimentar: $\mathrm{CA}=($ consumo de ração $) \div($ ganho de peso); ganho em comprimento total (medido do focinho ao final da nadadeira caudal); ganho em comprimento padrão (medido do focinho ao início da nadadeira caudal); altura ( medida à frente do $1^{\circ}$ raio da nadadeira dorsal); largura (medida à frente do $1^{\mathrm{o}}$ raio da nadadeira dorsal); taxa de crescimento específico $=[(($ In peso final - In peso inicial $) \div$ tempo $)$ $\mathrm{x} 100]$ e rendimento de carcaça.

O fígado, a gordura visceral e as vísceras foram pesados individualmente para determinação do Índice hepatossomático: [(peso do fígado $\div$ peso da carcaça $) \times 100]$; Índice lipossomático: [(peso da gordura intraperitoneal $\div$ peso da carcaça) $\times 100$ ] e Índice viscerossomática: (peso das vísceras $\div$ peso da carcaça) $\times 100]$.

\section{Ensaio II - Taxa de excreção de Amônia de tilápias em função da suplementação enzimática}

$\mathrm{O}$ ensaio foi realizado visando a quantificar a taxa de amônia total $\left(\mathrm{NH}_{3}+\mathrm{NH}_{4}\right)$ excretada pelos animais alimentados com a dieta reformulada sem e com adição do complexo enzimático nos níveis de 0,$025 ; 0,050$ e $0,075 \%$ totalizando quatro tratamentos e com quatro repetições. A estrutura física consistiu de 14 aquários com capacidade para
2,5 litros, aeração constante por meio de compressor e pedras porosas, e aquecedores individuais de 2,5 watts.

Os parâmetros da qualidade da água ( $\mathrm{pH}$, oxigênio dissolvido e temperatura) foram mensurados em todos os aquários individualmente com o auxílio de um peagâmetro (HANNA $\left.{ }^{\circledR}\right)$ e oxímetro/termômetro (ICEL $\AA$ ) durante o período de coleta da água.

Foram utilizados exemplares de tilápia do nilo, da linhagem Supreme com peso médio inicial de $21 \pm 0,4 \mathrm{~g}$. Os animais permaneceram nos aquários de alimentação por um período de 24 horas, sendo alimentados as 8h00min; 11h00min; 14h00min e 16h00min. Após um período de adaptação de sete dias, as coletas de água foram realizadas durante um período experimental de 15 dias.

No dia seguinte ao período descrito como "alimentação", após fornecimento de ração no primeiro horário da manhã (08h00min), os peixes foram transferidos para os aquários descritos como "aquários de coleta" onde permaneciam em jejum durante as 24 horas do período da coleta. Essas coletas da água foram realizadas as 0:00; 2:00; 4:00; 8:00; 12:00 e 24:00 horas após alimentação. Diariamente os aquários foram lavados e era realizada troca total de água. Para a coleta da água foram utilizados potes plásticos previamente lavados com solução de ácido clorídrico $10 \%$ e água destilada. Em seguida, as amostras foram congeladas e mantidas sobre refrigeração.

Para quantificar o teor de amônia total presente na água as análises foram realizadas segundo metodologia descrita por Koroleff (1976) utilizando espectofotômetro de absorção visível e realizando a leitura em densidade ótica de $650 \mathrm{~nm}$. A partir da leitura da absorbância foi obtido o teor de amônia total em miligramas por litro, possibilitando quantificar a taxa de excreção de amônia por meio da equação: Taxa de Excreção Endógena $=(\mathrm{C} 0$ - C1 $)$ x V $\div(\mathrm{W}$ x T $)$. Onde, $\mathrm{C} 0$ = concentração de amônia no tempo $2 ; \mathrm{C} 1$ = concentração de amônia no tempo 1; $\mathrm{V}=$ volume do aquário (em litros); $\mathrm{W}=$ peso do peixe $(\mathrm{kg}) ; \mathrm{T}=$ lapso de tempo (horas).

Os dados obtidos foram submetidos à análise de variância, e em caso de diferenças aplicou-se análise de regressão polinomial e comparação de médias por contrastes para os parâmetros de desempenho, biométricos e índices corporais. O teste de Tukey $(\mathrm{p}>0,05)$ foi realizado para análise da taxa de excreção de amônia.

\section{Resultados e Discussão}

\section{Experimento I - Desempenho de tilápias em função da suplementação enzimática}

No experimento I, os valores médios de oxigênio dissolvido, dureza, alcalinidade, $\mathrm{pH}$ e temperatura foram, respectivamente, $4,7 \pm 0,17 \mathrm{mg} / \mathrm{L} ; 54 \pm 8 \mathrm{mg} / \mathrm{L} ; 13,2 \pm 1,62$ $\mathrm{mg} / \mathrm{L} ; 6,7 \pm 1,67 ; 24,3 \pm 0,92\left({ }^{\circ} \mathrm{C}\right)$, permanecendo dentro da faixa aceitável para o bom desempenho da espécie. Não foram observadas mortes de peixes nas unidades experimentais.

Os valores médios para consumo de ração não apresentaram diferenças significativas $(\mathrm{P}>0,05)$. As tilápias que receberam a ração padrão obtiveram os melhores valores para peso final, ganho de peso e conversão alimentar quando comparadas, por meio de contraste, às que receberam ração reformulada, sem e com, inclusão do complexo enzimático 
(Tabela 2); no entanto, quando realizada a análise de contrastes entre os grupos de tilápia do nilo que receberam dieta reformulada e dieta reformulada + complexo enzimático, os melhores resultados para peso final $(86,64 \mathrm{~g})$ foram obtidos para peixes alimentados com dietas contendo enzimas exógenas. Os animais que receberam ração reformulada sem adição do complexo enzimático apresentaram peso final médio de $81,37 \mathrm{~g}$ (Figura 1).

Tabela 2: Desempenho de tilápias do nilo alimentadas com dieta padrão em comparação a dieta reformulada com suplementação em níveis do complexo enzimático.

\begin{tabular}{|c|c|c|c|c|c|}
\hline Dieta & Peso inicial (g) & Peso final (g) & $\begin{array}{c}\text { Ganho em peso } \\
(\mathrm{g})\end{array}$ & $\begin{array}{l}\text { Consumo de } \\
\text { ração }(\mathrm{g})\end{array}$ & $\begin{array}{c}\text { Conversão } \\
\text { alimentar (g:g) }\end{array}$ \\
\hline Padrão & 16,79 & 106,88 & 90,36 & 156,32 & 1,73 \\
\hline \multicolumn{6}{|l|}{ Reformulada } \\
\hline$(0,00)$ & 17,62 & 81,37 & 63,75 & 123,67 & 1,94 \\
\hline 0,025 & 16,95 & 82,91 & 65,35 & 126,12 & 1,93 \\
\hline 0,05 & 17,88 & 91,71 & 73,66 & 143,63 & 1,95 \\
\hline 0,075 & 18,11 & 85,3 & 67,19 & 137,73 & 2,05 \\
\hline Efeito & $0,35 \mathrm{~ns}$ & $0,001^{*}$ & $0,001 *$ & $0,26 \mathrm{~ns}$ & $0,017^{*}$ \\
\hline \multicolumn{6}{|l|}{ Contraste } \\
\hline $\mathrm{P} \times \mathrm{R}$ & NS & $106,88 \times 81,37$ & $90,36 \times 63,75$ & NS & $1,73 \times 1,94$ \\
\hline$P \times R E$ & NS & $106,88 \times 86,64$ & $90,36 \times 68,73$ & NS & $1,73 \times 1,97$ \\
\hline $\mathrm{R} \times \mathrm{RE}$ & NS & $81,37 \times 86,64$ & $63,75 \times 68,73$ & NS & NS \\
\hline Regressão & NS & NS & NS & NS & NS \\
\hline $\mathrm{CV}(\%)$ & 5,72 & 4,13 & 4,62 & 8,71 & 5,94 \\
\hline
\end{tabular}

$\mathrm{P}=$ dieta padrão; $\mathrm{R}$ = dieta reformulada redução de $10 \%$ da energia bruta, proteína bruta, fósforo e cálcio; $\mathrm{RE}=$ dieta reformulada com suplementação de complexo enzimático.

Em experimento realizado com juvenis de tilápia do Nilo, Moura et al. (2012), observaram melhores valores para o peso final e ganho em peso dos peixes alimentados com dietas contendo $0,025 \%$ de um complexo enzimático SSF (produzido por fermentação em estado sólido), sugerindo que a inclusão do aditivo promove resultados benéficos à nutrição da espécie.

As enzimas são proteínas que aceleram reações e quebram ligações entre moléculas, disponibilizando nutrientes que muitas vezes não poderiam ser absorvidos pelo organismo animal devido à impossibilidade deste produzir enzimas que atuem sobre um determinado substrato (CAMPESTRINI et al., 2005). A inclusão do complexo enzimático pode ter disponibilizado maior quantidade de nutrientes, os quais poderiam estar agrupados em compostos complexos cuja degradação não pode ser realizada, ou não foi de forma eficiente, pelas enzimas endógenas produzidas pelas tilápias do Nilo.

A inclusão de complexos enzimáticos ou enzimas digestivas em dietas para peixes representa uma alternativa viável, permitindo que alguns nutrientes sejam prontamente disponibilizados para a absorção pelo organismo animal, influenciando de forma positiva no desempenho zootécnico de diversas espécies a exemplo de peixes ornamentais (SIGNOR et al., 2013) e a tilápia do Nilo (SIGNOR et al., 2010).

Quando realizada a análise de contrastes entre dieta padrão e reformulada para peso final (g) foi observado que os animais pertencentes ao grupo que recebeu a ração padrão apresentaram melhores valores 106,88 (g) (Figura 1). Para os contrastes entre os grupos de tilápia do nilo que receberam dieta reformulada e ração reformulada com inclusão em níveis do complexo enzimático, os melhores resultados para peso final $(86,64 \mathrm{~g})$ foram obtidos para animais alimentados com dietas contendo enzimas exógenas. Os animais que receberam ração reformulada sem adição do complexo enzimático apresentaram peso final médio de $81,37 \mathrm{~g}$.

Os animais alimentados com ração reformulada com inclusão em níveis do complexo enzimático apresentaram maior ganho de peso $(68,06 \mathrm{~g})$ do que os alimentados sem o complexo enzimático 63,75g (Figura 2).

Figura 1: Contrastes entre a dieta padrão $(\mathrm{P})$, dieta reformulada sem $(\mathrm{R})$ e com níveis do complexo enzimático $(\mathrm{RE})$ para o peso final (g) em tilápias do Nilo.

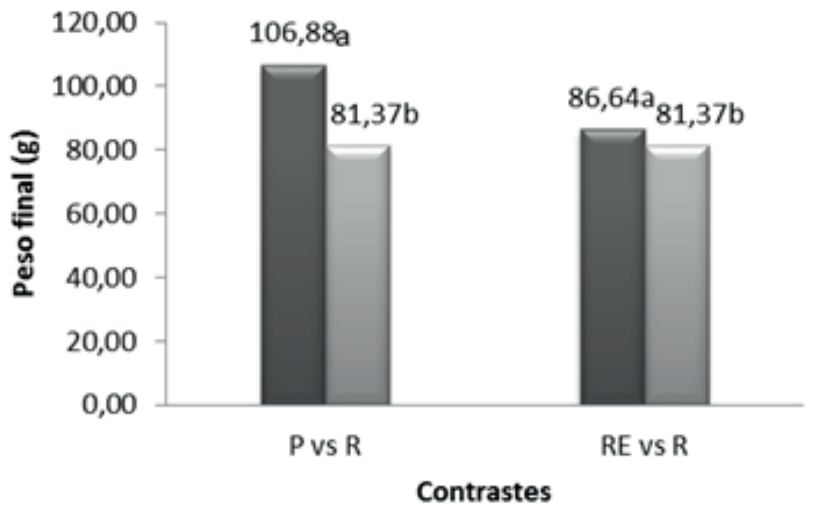


Figura 2: Contrastes entre a dieta padrão $(\mathrm{P})$, dieta reformulada sem $(\mathrm{R})$ e com níveis do complexo enzimático (RE) para ganho em peso $(\mathrm{g})$ de tilápias do Nilo.

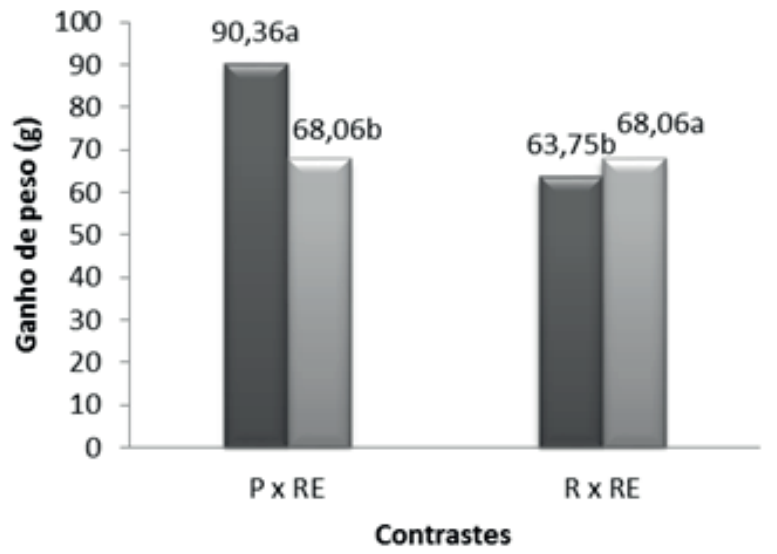

Entre os peixes que receberam a dieta reformulada, a inclusão do complexo enzimático promoveu maior ganho em comprimento padrão $(5,75)$ e ganho em largura $(0,88$ $\mathrm{cm}$ ), demonstrando que a inclusão do complexo enzimático mesmo em dietas com redução energética, proteica, de cálcio e fósforo pode influenciar de maneira positiva no ganho em comprimento padrão e largura. Sendo observado efeito quadrático para a inclusão do complexo enzimático sobre o comprimento padrão dos animais (Tabela 3).

Em experimento com peixes ornamentais onívoros, Gomes et al. (2017), testando a eficiência das enzimas digestivas fitase, protease e alfa-amilase em rações para o peixe guppy (Poecilia reticulata) na fase de crescimento, verificaram que a inclusão proporcionou maior ganho em largura, peso final e melhor conversão alimentar.

Tabela 3: Ganhos em comprimento total, padrão, altura, largura e taxa de crescimento específico de tilápias do nilo alimentadas com dieta padrão em comparação a dieta reformulada com suplementação do complexo enzimático.

\begin{tabular}{|c|c|c|c|c|c|}
\hline Dieta & $\begin{array}{c}\text { Ganho em } \\
\text { comprimento } \\
\text { total }\end{array}$ & $\begin{array}{c}\text { Ganho em } \\
\text { comprimento } \\
\text { padrão }^{1} \\
\end{array}$ & Ganho em altura & $\begin{array}{c}\text { Ganho em } \\
\text { largura }\end{array}$ & $\begin{array}{c}\text { Taxa de } \\
\text { crescimento } \\
\text { específico }\end{array}$ \\
\hline Padrão & 7,83 & 6,11 & 2,5 & 1,13 & 3,08 \\
\hline Reformulada $(0,00)$ & 6,37 & 4,94 & 2,06 & 0,76 & 2,54 \\
\hline 0,025 & 6,25 & 5,74 & 2,13 & 0,84 & 2,66 \\
\hline 0,05 & 7,2 & 5,43 & 2,29 & 0,88 & 2,72 \\
\hline 0,075 & 6,5 & 5,02 & 2,08 & 0,88 & 2,58 \\
\hline Efeito & $0,001 *$ & $0,001 *$ & $0,007 *$ & $0,001^{*}$ & $0,001 *$ \\
\hline \multicolumn{6}{|l|}{ Contrate } \\
\hline $\mathrm{P} \times \mathrm{R}$ & $7,83 \times 6,37$ & $6,11 \times 4,94$ & $2,50 \times 2,06$ & $1,13 \times 0,76$ & $3,08 \times 2,54$ \\
\hline $\mathrm{P} \times \mathrm{RE}$ & $7,83 \times 6,65$ & $6,11 \times 5,40$ & $2,50 \times 2,16$ & $1,13 \times 0,87$ & $3,08 \times 2,65$ \\
\hline $\mathrm{R} \times \mathrm{RE}$ & NS & $4,94 \times 5,40$ & NS & $0,76 \times 0,87$ & NS \\
\hline Regressão & NS & Q & NS & NS & NS \\
\hline $\mathrm{CV}(\%)$ & 4,05 & 4,99 & 7,33 & 5,91 & 2,69 \\
\hline
\end{tabular}

Para a taxa de crescimento específico o maior valor médio foi obtido nas tilápias alimentadas com a dieta padrão $(3,08)$, não havendo diferenças significativas entre os valores médios para taxa de crescimento específico dos animais que receberam dieta reformulada $(2,54)$ e ração reformulada com inclusão de enzimas exógenas $(2,65)$.

Os índices víscerossomáticos, hepatossomático, lipossomático e o rendimento de carcaça (Tabela 4) não apresentaram diferenças significativas $(\mathrm{P}<0,05)$ entre os peixes que receberam a dieta padrão e a dieta reformulada sem e com inclusão de enzimas exógenas.

$\mathrm{O}$ índice hepatossomático pode ser considerado um indicador de atividade biológica (ROTTA, 2003), visto que o fígado possui alta atividade metabólica. Segundo Lopes et al. (2010), as reservas energéticas do fígado podem ser mobilizadas visando suprir, em parte, o déficit energético das rações ou em resposta a ação de fatores antinutricionais presentes nos alimentos. 
Tabela 4: Índices víscerossomático, hepatossomático, lipossomático e rendimento de carcaça de Tilápia do nilo alimentadas com dieta padrão e reformulada com suplementação com complexo enzimático.

\begin{tabular}{|c|c|c|c|c|}
\hline Dieta & $\begin{array}{c}\text { Índice } \\
\text { Viscerossomatico (\%) }\end{array}$ & $\begin{array}{c}\text { Índice } \\
\text { Hepatossomático (\%) }\end{array}$ & $\begin{array}{c}\text { Índice Lipossomático } \\
(\%)\end{array}$ & $\begin{array}{c}\text { Rendimento de } \\
\text { Carcaça (\%) }\end{array}$ \\
\hline Padrão & 13,05 & 1,72 & 1,08 & 86,95 \\
\hline Reformulada $(0,00)$ & 14,96 & 2,31 & 0,81 & 85,39 \\
\hline 0,025 & 12,92 & 1,87 & 0,7 & 86,45 \\
\hline 0,050 & 14,41 & 1,62 & 0,88 & 85,72 \\
\hline 0,075 & 13,86 & 1,97 & 0,58 & 87 \\
\hline Efeito & $0,270 \mathrm{~ns}$ & $0,440 \mathrm{~ns}$ & $0,166 \mathrm{~ns}$ & $0,270 \mathrm{~ns}$ \\
\hline \multicolumn{5}{|l|}{ Contrate } \\
\hline $\mathrm{P} \times \mathrm{R}$ & NS & NS & NS & NS \\
\hline$P \times R E$ & NS & NS & $1,08 \times 0,72$ & NS \\
\hline $\mathrm{R} \times \mathrm{RE}$ & NS & NS & NS & NS \\
\hline Regressão & NS & NS & NS & NS \\
\hline CV (\%) & 8,83 & 15,60 & 22,64 & 1,40 \\
\hline
\end{tabular}

$\mathrm{P}=$ dieta padrão; $\mathrm{R}$ = dieta reformulada redução em $10 \%$ da energia bruta, proteína bruta, cálcio e fósforo; $\mathrm{RE}=$ dieta reformulada com níveis do complexo enzimático.

Adição de enzimas ou complexos enzimáticos em rações para não ruminantes tem apresentado resultados positivos em dietas com redução energética para poedeiras comerciais (VIANA et al., 2011) e frangos de corte (BARBOSA et al., 2012), porém, pesquisas com redução proteica e inclusão de complexo enzimática para peixes ainda são escassas.

A inclusão do complexo enzimático não foi suficiente para suprir a redução de $10 \%$ em proteína, energia, cálcio e fósforo na dieta para tilápias do Nilo. Iwahashi et al. (2011), utilizando redução proteica e energética de $2 \%$ e $4 \%$ e adição $(0,05 \%)$ do complexo enzimático composto por xilanase e $\beta$-glucanase, verificaram que com a suplementação enzimática foi possível reduzir em até $160 \mathrm{kcal} / \mathrm{kg}$ de energia bruta, sem prejudicar o desempenho inicial das codornas. No entanto, para animais entre 15 e 35 dias, a suplementação enzimática não foi capaz de suprir a redução de $4 \%$ em energia metabolizável, provocando aumento no consumo de ração, menor ganho em peso e maior custo de produção.

\section{Experimento II - Taxa de excreção de Amônia de tilápias em função da suplementação enzimática}

A temperatura e a concentração de oxigênio dissolvido ( $\mathrm{mg} \mathrm{L}^{-1}$ ) foram controlados, por isso não foram influenciados pela inclusão do complexo enzimático ou pela redução de nutrientes nas dietas reformuladas. $\mathrm{O}$ pH (potencial hidrogênio iônico) apresentou diferenças $(\mathrm{P}<0,05)$ em relação ao tempo que os peixes passaram no sistema de coletas de água se apresentando mais elevado $(7,45 \pm 0,18)$ durante as primeiras duas horas, quando comparado ao verificado após quatro horas $(6,73 \pm 0,17)$ e até 24 horas $(6,73 \pm 0,17)$. Esse parâmetro é importante na produção de organismos aquáticos devido a sua profunda influência no metabolismo do peixe, atuando nos processos de permeabilidade da membrana celular e sobre a toxidade de certos compostos como a amônia. Durante o experimento o $\mathrm{pH}$ se manteve dentro da faixa adequada para a produção de peixes.

A inclusão do complexo enzimático interferiu $(\mathrm{P}<0,05)$ na excreção de amônia de tilápias do Nilo (Figura 3). A taxa de excreção de amônia não foi constante durante o período de 24 horas, apresentando pico de excreção as quatro horas após alimentação nas tilápias que receberam a dieta sem adição do complexo enzimático.

O maior pico de excreção para os animais que receberam ração com $0,025 \%$ e $0,050 \%$ foram observados oito horas pós-prandial. O grupo de peixes que recebeu ração com adição de $0,075 \%$ do complexo enzimático não apresentou sincronia de excreção, porém, a maior taxa de excreção de amônia (mg/kg/h) ocorreu duas horas após alimentação.

De uma forma geral, os animais que receberam a dieta sem suplementação do complexo enzimático apresentaram maiores taxas de excreção de amônia, enquanto as menores taxas de excreção de amônia $(\mathrm{mg} / \mathrm{kg} / \mathrm{h})$ foram dos peixes que receberam a dieta com inclusão de $0,025 \%$ do complexo enzimático. 
Figura 3: Taxas de excreção de amônia total $(\mathrm{mg} / \mathrm{kg} / \mathrm{h})$ de juvenis de Tilápia, Oreochomis nilóticus, em relação ao nível de inclusão de enzimas exógenas durante período de 24 horas após a alimentação.

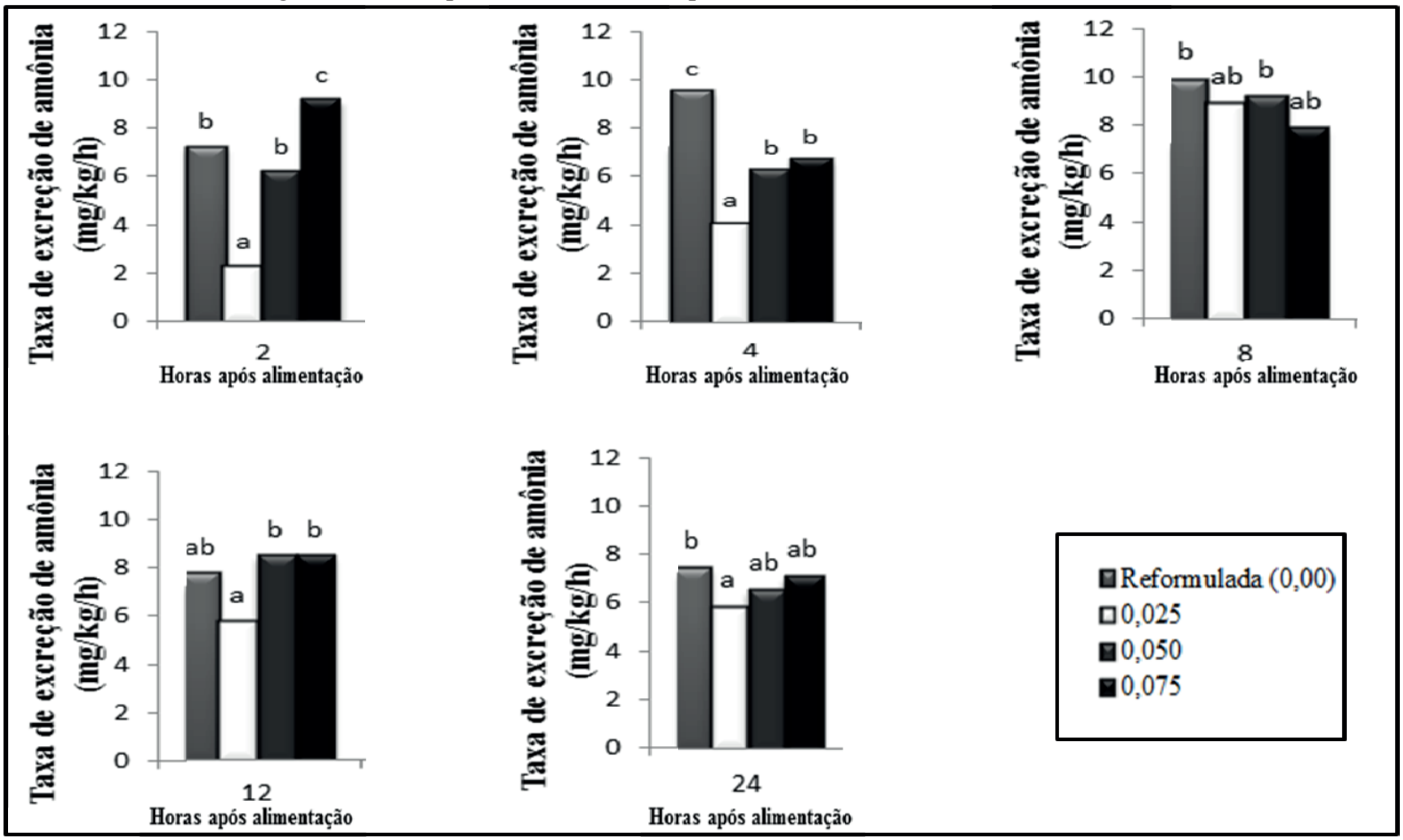

Em juvenis de tambaqui alimentados com dietas com teor crescente de proteína, picos de excreção de amônia ocorreram quatro horas após alimentação e diminuíram de forma gradativa até 24 horas pós-prandial (SILVA NETO et al., 2012). Pampos juvenis submetidos a dietas com níveis crescentes de proteína bruta (\%) apresentaram picos mais altos de excreção de amônia, após seis horas de coleta, quando alimentados com os maiores níveis testados (SILVA et al., 2015).

Em sistemas de produção de peixes altas concentrações de amônia podem representar risco à saúde e crescimento, impedindo a formação de proteínas e podem levar a morte dos animais (PARKER; DAVIS, 1981, apud CAVERO et al., 2004).

\section{Conclusões}

Recomenda-se suplementação de dietas com complexo enzimático para tilápia do Nilo na fase de juvenil, embora, não seja recomendada a utilização de rações com redução em $10 \%$ de proteína bruta, energia bruta, cálcio e fósforo.

A inclusão de $0,025 \%$ do complexo enzimático possibilita menores taxas de excreção de amônia $(\mathrm{mg} / \mathrm{kg} / \mathrm{h})$, sendo recomendada a utilização do complexo como medida auxiliar a redução de excreção de amônia no ambiente de cultivo.

\section{Agradecimentos}

À Coordenação de Aperfeiçoamento de Pessoal de Nível Superior (CAPES) e às empresas Alltech ${ }^{\circledR}$ e Guara$\operatorname{ves}{ }^{\circledR}$.

\section{Referências}

BARBOSA, N. A. A. et al. Enzimas exógenas em dietas de frangos de corte: desempenho. Ciência Rural, Santa Maria, v. 42 , n. 8 , ago. 2012 .

CAMPESTRINI, E.; SILVA, V. T. M. DA; APPELT, M. D. Utilização de enzimas na alimentação animal. Revista Eletrônica Nutritime, v. 2, n. 6, p. 259-272, 2005.

CAVERO, B. A. S. et al. Tolerância de juvenis de pirarucu ao aumento da concentração de amônia em ambiente confinado. Pesquisa Agropecuária Brasileira, v. 5, p. 513-516. 2004.

FURUYA, W. M. Tabelas Brasileiras para a Nutrição de Tilápias. Toledo: GFM. 100p. 2010.

GOMES, V. D. S. et al. Enzimas exógenas na alimentação do peixe guppy (Poecilia reticulata). Archives of Veterinary Science. v. 22, n. 3, p. 24-29, 2017.

GUIMARÃES, I. G. et al. Digestibilidade aparente de rações contendo complexo enzimático para tilápia-do-nilo. Arquivo Brasileiro de Medicina Veterinária e Zootecnia, v. 61, n. 6, p. 1397-1402, 2009.

KOROLEFF, F. Determination of nutrients. In: GRASSHOFFK, K. Methods of seawater Analysis. Germany: Verlag Chemie Weinhein. p. 117-187, 1976.

LOPES, J. M. et al. Farelo de babaçu em dietas para tambaqui. Revista Brasileira de Saúde e Produção Animal, v.11, n. 2, p. 519-526, 2010. 
MENDONÇA, P. P. et al. Efeito da suplementação de fitase na alimentação de juvenis de tambaqui (Colossoma macropomum). Archives de Zootecnia. v. 61, n. 235, p. 437-448. 2012.

MOREIRA, H. L. M. Fundamentos da moderna aquicultura. Editora da ULBRA, 2001.

MOURA, G. S. et al. Effects of enzyme complex SSF (solid state fermentation) in pellet diets for Nile tilapia. Revista Brasileira de Zootecnia. v. 41, n. 10, p. 2139-2143, 2012

OLIVEIRA, G. R. et al. Digestibilidade de nutrientes em ração com complexo enzimático para tilápia-do-nilo. Revista Brasileira de Zootecnia, v. 36, n. 6, p. 1945-1952, 2007.

ROCHA, C. B. et al. Fitase na dieta de alevinos de carpa húngara: desempenho e características de carcaça. Arquivos Brasileiros de Medicina Veterinária e Zootecnia, v. 62, n. 6, p. 1462-1468, 2010.

RODRIGUES, R. B. et al. Tecnologia de bioflocos no cultivo de tilápia do nilo (Oreochromis niloticus). Acta Tecnológica, v. 10, n. 2, p. 75-89, 2017.

ROTTA, M. A. Aspectos gerais da fisiologia e estrutura do sistema digestivo dos peixes relacionados à piscicultura. Corumbá: Embrapa Pantanal, 2003. p. 11-22, 2003.

SIGNOR, A. A. et al. Desempenho de juvenis de Tilápia-donilo alimentados com rações contendo complexo enzimático. Revista Brasileira de Zootecnia, v. 39, n. 5, p. 977-983, 2010.

SIGNOR, A. A. et al. Complexo enzimático na dieta de alevinos de kinguio (Carassius auratus). Semina: Ciências Agrárias, Londrina, v. 34, n. 3, p. 1381-1388, 2013.

SILVA, E. M. et al. Crescimento e metabolismo do nitrogênio em juvenis de Trachinotus marginatus alimentados com diferentes níveis proteicos. Arquivo Brasileiro de Medicina Veterinária e Zootecnia, v. 67, n. 1, p. 131-139. 2015.

SOARES, E. C. et al. Protease exógena em dietas para juvenis de tucunaré-paca (Cichla sp.). Revista Brasileira de Zootecia, v. 37, n. 6, p. 971-976, 2008.

TESSER, M. B. et al. Suplementação de enzimas exógenas em dieta microparticulada para larvicultura do pacu. Revista Brasileira de Zootecia, v. 35, n. 6, p. 2211-2218, 2006.

VIANA, M. T. S. et al. Utilização de xilanase em dietas compostas por milho e farelo de soja de poedeiras comerciais em postura. Revista Brasileira de Zootecnia, v. 40, n. 2, p. 385-390. 2011.

YILDIRIM, Y. B.; TURAN, F. Effects of exogenous enzyme supplementation in diets on growth and feef utilization in African Catfish, Clarias gariepinus. Jornal of Animal and Veterinary Advances v. 9, n. 2, p. 327-331, 2010.
Recebido em: 11.06.2018

Aceito em: 24.03.2019 